\title{
Impact of electroacupuncture on quality of life for patients with Relapsing-Remitting Multiple Sclerosis under treatment with immunomodulators: A randomized study
}

\author{
Juan G Quispe-Cabanillas ${ }^{1,2^{*}}$, Alfredo Damasceno ${ }^{1,4}$, Felipe von Glehn ${ }^{1,4}$, Carlos O Brandão ${ }^{1,4}$,
} Benito P Damasceno ${ }^{4}$, Wanderley D Silveira ${ }^{3}$ and Leonilda MB Santos ${ }^{1}$

\begin{abstract}
Background: Multiple sclerosis (MS) is a complex autoimmune disease mediated by an immune response to central nervous system antigens. Modern immunomodulatory therapies, however, do not ameliorate many of the symptoms, such as pain and depression. Patients thus seek alternative treatments, such as acupuncture, although the benefits of such treatments have not been objectively evaluated. The present study was thus designed to evaluate the effect of the use of acupuncture in the alleviation of the symptoms of patients with MS.
\end{abstract}

Methods: Thirty-one patients with Relapsing-Remitting Multiple Sclerosis undergoing treatment with immunomodulators were randomly distributed into sex-stratified experimental and placebo groups in a patientand evaluator-blind design; they received either true or sham electroacupuncture during regular visits to the doctor in the university hospital outpatient clinic. Standardized questionnaires were used to evaluate the effect of electroacupuncture on the quality of life of these patients. Initial and follow-up assessment included the evaluation of clinical status (Expanded Disability Status Scale), pain (Visual Analogue Scale) and quality of life (Functional Assessment of multiple Sclerosis) to ascertain the impact of electroacupuncture on the quality of life of these patients.

Results: Electroacupuncture improved various aspects of quality of life, including a reduction in pain and depression. The self-report scales were more sensitive to improvement than was the more objective clinical measure.

Conclusion: This paper provides evidence that electroacupuncture can significantly improve the quality of life of such patients. The results suggest that the routine use of a self-report scale evaluating quality of life should be included in regular clinical evaluations in order to detect changes more rapidly.

Trial Registration: RBR-58yq52

Keywords: Multiple sclerosis, Electroacupuncture, Pain, Depression, Chinese traditional medicine, Symptoms, Quality of life, Randomised control trial, Expanded disability status scale

\footnotetext{
* Correspondence: juangqc@fcm.unicamp.br

${ }^{1}$ Neuroimmunology Unit, Department of Genetics, Evolution and Bioagents,

University of Campinas (UNICAMP), Campinas, SP, Brazil

${ }^{2}$ Department of Clinical Medicine, University of Campinas (UNICAMP),

Campinas, SP, Brazil

Full list of author information is available at the end of the article
} 


\section{Background}

Multiple sclerosis is a complex autoimmune disease mediated by the individual immune response against central nervous system (CNS) antigens. Its causes are unknown, although, both genetic and environmental components play important roles and interact to produce susceptibility to the disease and influence its course [1]. For the relapsing-remitting type of multiple sclerosis (RRMS), various immunomodulatory therapies have been developed, with an effectiveness of some $35 \%$, and these have had a significant impact on the natural history of the disease [2-4]. However, although these agents do reduce the relapse rate, they do not ameliorate many of the symptoms and lead to undesirable side effects [5]. Patients may still complain of diverse symptoms, such as difficulty in walking, incontinence, impaired sexual function, and pain, all of which lead to a poor quality of life (QOL) [6], and many seek alternative treatments such as acupuncture. Acupuncture, which is an important component of Traditional Chinese Medicine (TCM), involves the insertion of metallic needles into specific points, stimulating them either manually or electrically (eletroacupuncture) [7]. Its increase in popularity during recent years has not gone unnoticed by the medical community with clinical trials using acupuncture for the alleviation of pain and stroke rehabilitation [8-12]. Nevertheless, few reports address the benefits of this treatment on the quality of the life of RRMS patients [13]. Our aim was thus to study the effect of electroacupuncture on the QOL of patients with RRMS undergoing treatment with immunomodulators, using standardized questionnaires to evaluate these effects.

\section{Method}

\section{Subjects}

The study was carried out in the MS outpatient clinic of the University of Campinas Hospital (UNICAMP) in Campinas in the State of São Paulo in Brazil between 2008 and 2010. A total of 167 patients with a confirmed diagnosis of RRMS according to the revised 2010 McDonald criteria and under treatment with immunomodulatory drugs (interferon-beta and glatiramer acetate) were identified $[14,15]$. The sample selected consisted of all 31 living close enough to appear for weekly appointments and who had not previously received acupuncture treatment (Figure 1); these subjects were distributed into true acupuncture and placebo (sham acupuncture) groups. All patients provided informed consent and agreed to receive one of two interventions, either true electroacupuncture (TEA) or sham electroacupuncture (SEA). They were informed that it was possible that this procedure might or might not have any effect on their condition. The study was approved by the University of Campinas Committee for Ethical Research CAAE -

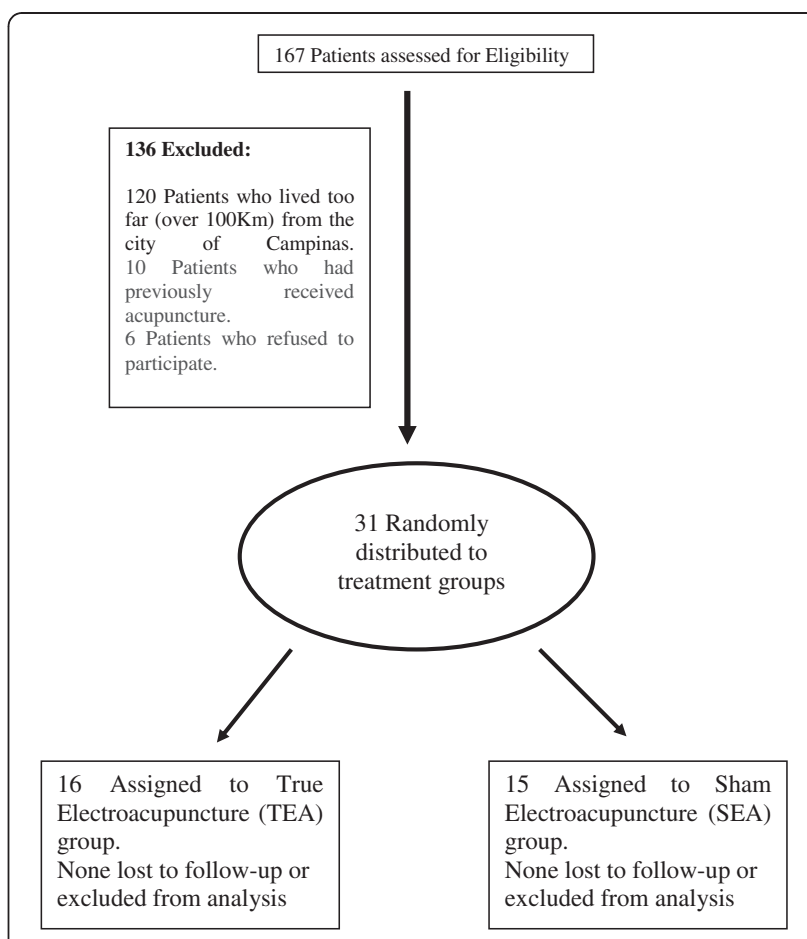

Figure 1 Flow diagram outlining participant selection.

0775.0.146.000-08 and The Brazilian Clinical Trials Registry (RBR-58yq52, http://ecgovbr2.bvsalud.org/).

\section{Randomization and blinding}

Simple randomization to allocate patients to equal parallel groups receiving TEA or SEA treatments was based on a table of random numbers, with the groups stratified by sex. The study involved a patient- and evaluator-blind design. Only the practitioner, an experienced acupuncturist with more than ten years of experience and accredited by the Brazilian National Council for Biomedicine in the area of acupuncture, was aware of the intervention to be used. Treatment was applied following individual schedules so that none of the patients had any contact with the others in the study. Moreover, all patients agreed not to have contact with other participants and to avoid talking about their treatment. Initial assessment included the application of three previously validated instruments to evaluate 1) clinical status (Expanded Disability Status Scale), 2) pain (Visual Analogue Scale) and 3) quality of life (Functional Assessment of multiple Sclerosis).

\section{Intervention}

All patients were receiving conventional treatment for RRMS, which involves a self-administered daily injection of interferon beta 1-a or interferon beta 1-b, and this treatment was continued throughout the present study 
[2-4]. Acupuncture was initiated after the determination of the two groups. The protocol consisted of 30 minutes of electroacupuncture (either true or sham) once a week for six consecutive months.

A single treatment protocol was developed for all patients on the basis of acupuncture points reported to stimulate the immune system [16-21]. Disposable stainless steel needles (diameter $0.20 \mathrm{~mm}$ x length $30 \mathrm{~mm}$; Dongbang, Republic of Korea) were used. For the experimental group, the needles were inserted bilaterally at the points Zusanli (ST36), Sanyinjiao (SP6), Hegu (LI4) and Quchi (LI11), with a ninth needle inserted at Yintang (EX-HN3); the location of the points, angle of insertion and depth of insertion were based on the references in a classic text of Chinese medicine [22]. The "de qi" (manifestation of sensation in response to the presences of the needle) was sought for each point. In the SEA group, needle insertion was more superficial (less than $0.2 \mathrm{~cm}$ ) and one centimeter to the side of the critical points used for the TEA group, with care taken to avoid areas corresponding to any of the 14 meridians of TCM. After the needles were inserted, they were connected to the terminals of a six-channel KWD 808 serial impulse electrostimulator (Changzhou, China) set to run on alternating current and produce an electrical stimulus of $4 \mathrm{~Hz}$ in discontinuous waves, with a pulse width of $0.5 \mathrm{~ms}$. The stimulation was applied to each of the needles (except for that in Yintang) for the TEA group, while for the SEA group, no actual electrical stimulation was given.

\section{Outcome measures}

Clinical status was assessed prior to the treatment, as well as after six months, using the Expanded Disability Status Scale (EDSS), which is an instrument used to evaluate neurological impairment on a scale of 0 (normal capacity) to 10 (death) [23]. Quality of life was also assessed prior to the initiation of treatment, as well as after three and six months; it was measured by the Functional Assessment of Multiple Sclerosis (FAMS) instrument, validated for Portuguese [24,25]. Briefly, this is a disease-specific 44-item self-report questionnaire investigating patient perception of the quality of their lives, using a 5-point Likert-type scale ranging from "not at all" to "very much", which yields a score between 0 (for not at all) and 4 (for very much) for each of the items. The six sub-scales assess mobility, symptoms, emotional well being/depression, general contentment, thinking/fatigue, and family/social well being; moreover, patient observations of perceived changes in their lives with treatment were also noted. Pain was evaluated using the 10-point Visual Analogue Scale (VAS), applied just before each application of the FAMS. Miscellaneous improvements were occasionally mentioned by patients, and these were also noted.

\section{Statistical analysis}

Data were analyzed using SAS System for Windows software, version 9.2 (SAS Institute, Cary, NC, USA), with a Fisher/s exact test used to determine differences between proportions. The Mann-Whitney test was used for between-group comparisons of the parameters evaluated. An analysis of variance (ANOVA) test with repeated measures was used for between-group comparison of the ranked parameters, as well as to ascertain differences due to length of treatment. The statistical tests were twotailed, with level of significance set at 5\%.

\section{Results}

Figure 1 provides a flow diagram of the selection and treatment of the two groups, with sixteen in the TEA group and fifteen in the SEA. The groups were similar with respect to age, gender, and duration of the disease (Table 1).

\section{Clinical status}

The clinical evaluations based on the EDSS were similar for the two groups at the beginning of the study (initial means of 3.0 and 2.3 for the SEA and TEA groups, respectively $(p=0.3)$. After 6 months of treatment, however, the group receiving the SEA had shown somewhat more deterioration, although the difference between the two groups only approached significance (3.3 vs 2.2; $\mathrm{p}=0.055)$. Nevertheless, when including the effect of duration of treatment using the ANOVA test, there was a significant interaction effect, with the patients receiving the sham treatment receiving higher (worse) scores than those receiving true electroacupuncture $\left(\mathrm{P}_{\text {interaction effect }}=\right.$ 0.0338; Figure 2).

\section{Quality of life}

Although initial QOL scores for all subscales were similar for the two groups (with p-values ranging from 0.0985 to 0.5333 ), after treatment there was a significant difference between the groups ( $p$-values of 0.0026 and $<0.0001$ after three and six months, respectively). Only the thinking/fatigue subscale showed no significant difference between groups after treatment $(p=0.073$ for both time periods). These improvements are shown in Figures 2, 3, 4 and 5. The SEA group did show a

\section{Table 1 Participant characteristics}

\begin{tabular}{lccccccc}
\hline $\begin{array}{l}\text { Treatment } \\
\text { Group }\end{array}$ & \multicolumn{3}{c}{ Age } & & \multicolumn{3}{c}{ Gender } \\
\cline { 2 - 4 } \cline { 7 - 8 } & $\#$ & (years*) & SD & & F/M & $\begin{array}{c}\text { Years } \\
\text { with MS* }\end{array}$ & SD \\
\hline $\mathrm{SEA}^{1}$ & 15 & 40.1 & $(9.1)$ & $13 / 2$ & 9.3 & $(7.0)$ \\
$\mathrm{TEA}^{2}$ & 16 & 36.0 & $(11.5)$ & $14 / 2$ & 7.6 & $(6.0)$ \\
\hline
\end{tabular}

${ }^{*}$ Mean, ${ }^{1}$ sham electroacupuncture (SEA), ${ }^{2}$ true electroacupuncture (TEA). 


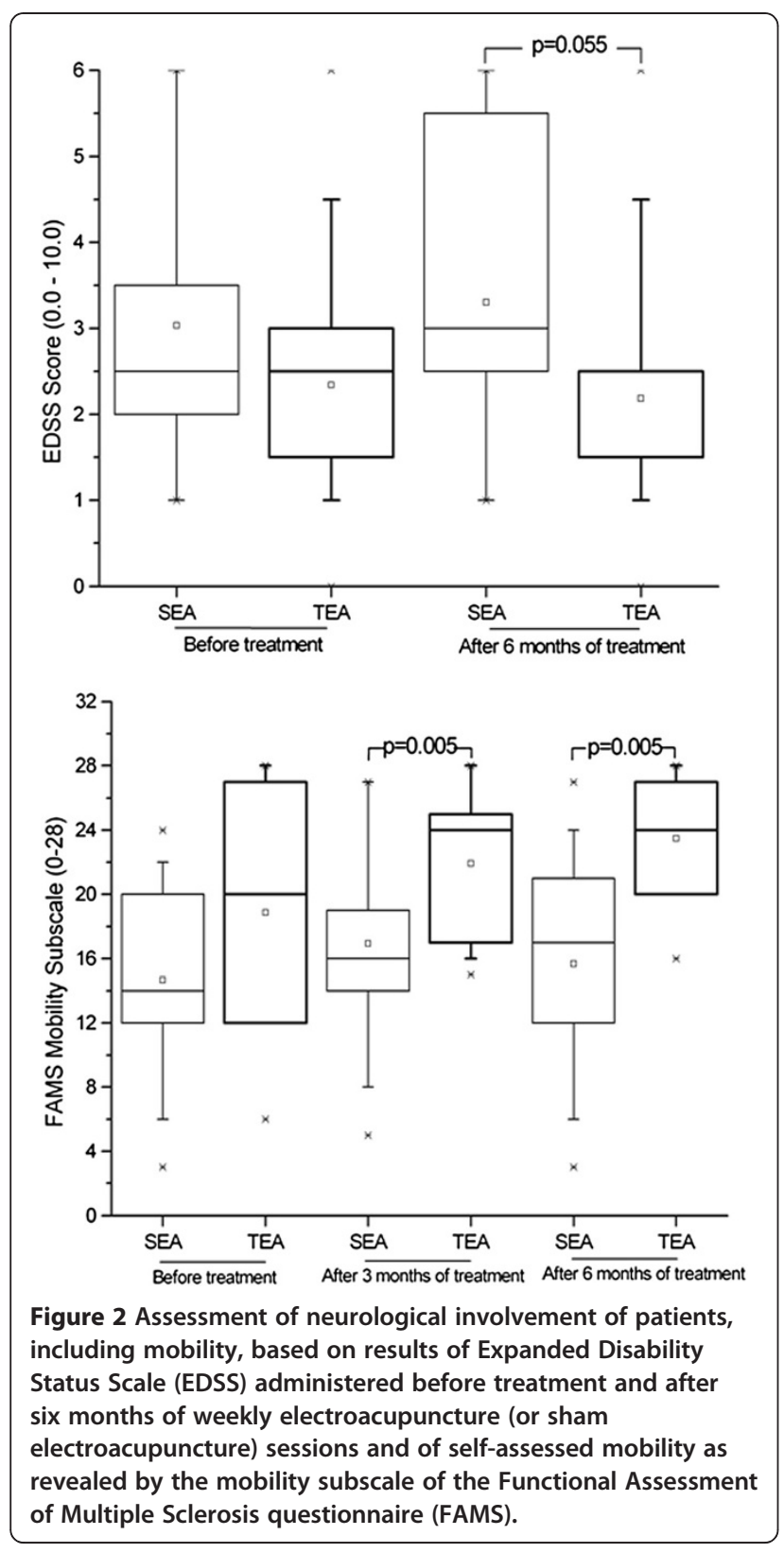

transitional improvement on the symptoms subscale after three months of treatment $(\mathrm{p}<0.01)$, but this did not persist to the end of treatment $(\mathrm{p}>0.10)$.

\section{Pain}

The presence of pain, evaluated by the VAS, was similar for the two groups prior to the initiation of the electroacupuncture treatment $(\mathrm{p}=0.42)$, but true electroacupuncture significantly reduced the pain felt by patients with RRMS, an effect observed after both three and six months ( $\mathrm{p}=0.014$ and 0.0001 , respectively). For the group receiving the sham treatment, there was an improvement after three months, $(\mathrm{p}=0.028)$, but the amelioration

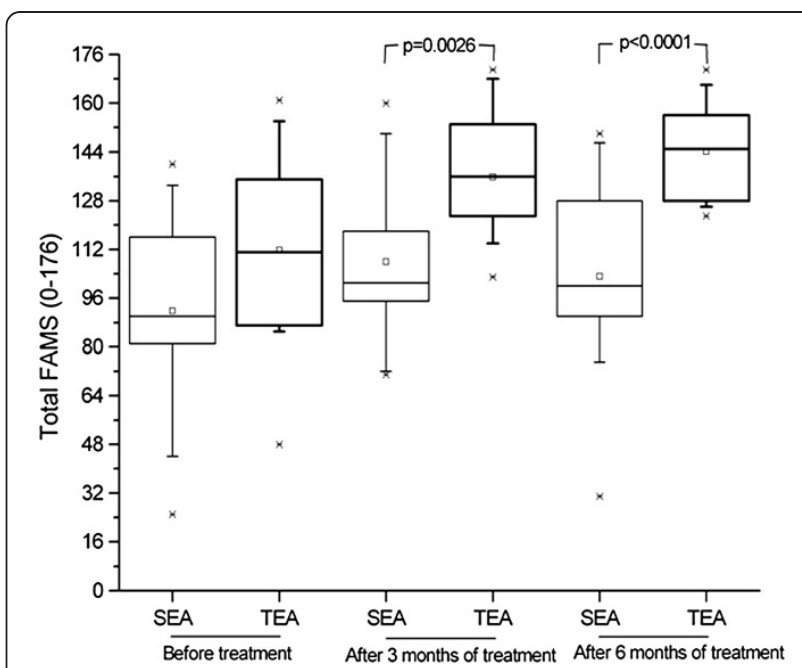

Figure 3 Overall Results of Functional Assessment of Multiple Sclerosis questionnaire (FAMS) administered prior to treatment, as well as after three and six months of weekly electroacupuncture (or sham electroacupuncture) sessions.

was not sustained to the end of the treatment $(\mathrm{p}=0.1)$ (Figure 6).

\section{Other effects}

In addition to the actual results of the study, the participants in the TEA group reported various improvements, such as better sleep and appetite and reduced incontinence and constipation; three participants in this group also reported the disappearance of leg spasms during treatment. Although these effects were not systematically measured, since they were not included in the initial study design, these reports suggest that the positive effects of acupuncture for patients with multiple sclerosis may go beyond the specific aspects of QOL measured. No adverse effects were reported by the patients in either group.

\section{Discussion}

As this study of electroacupuncture on RRMS patients has shown, the use of the technique does indeed improve QOL, which includes the general contentment of these patients, as well as family and social well-being. One of the most incapacitating aspects of the disease is the gradual loss of mobility with the advance of the disease [6]. This study included two measures of this mobility, the EDSS, assessed by a neurologist, and the self-report of mobility subscale of the FAMS. Although the results of the EDSS showed a slightly reduced advance in the results of neurological damage caused by the disease for the patients receiving TEA, the difference between the two groups only approached significance. The results of the mobility subscale of the FAMS, 


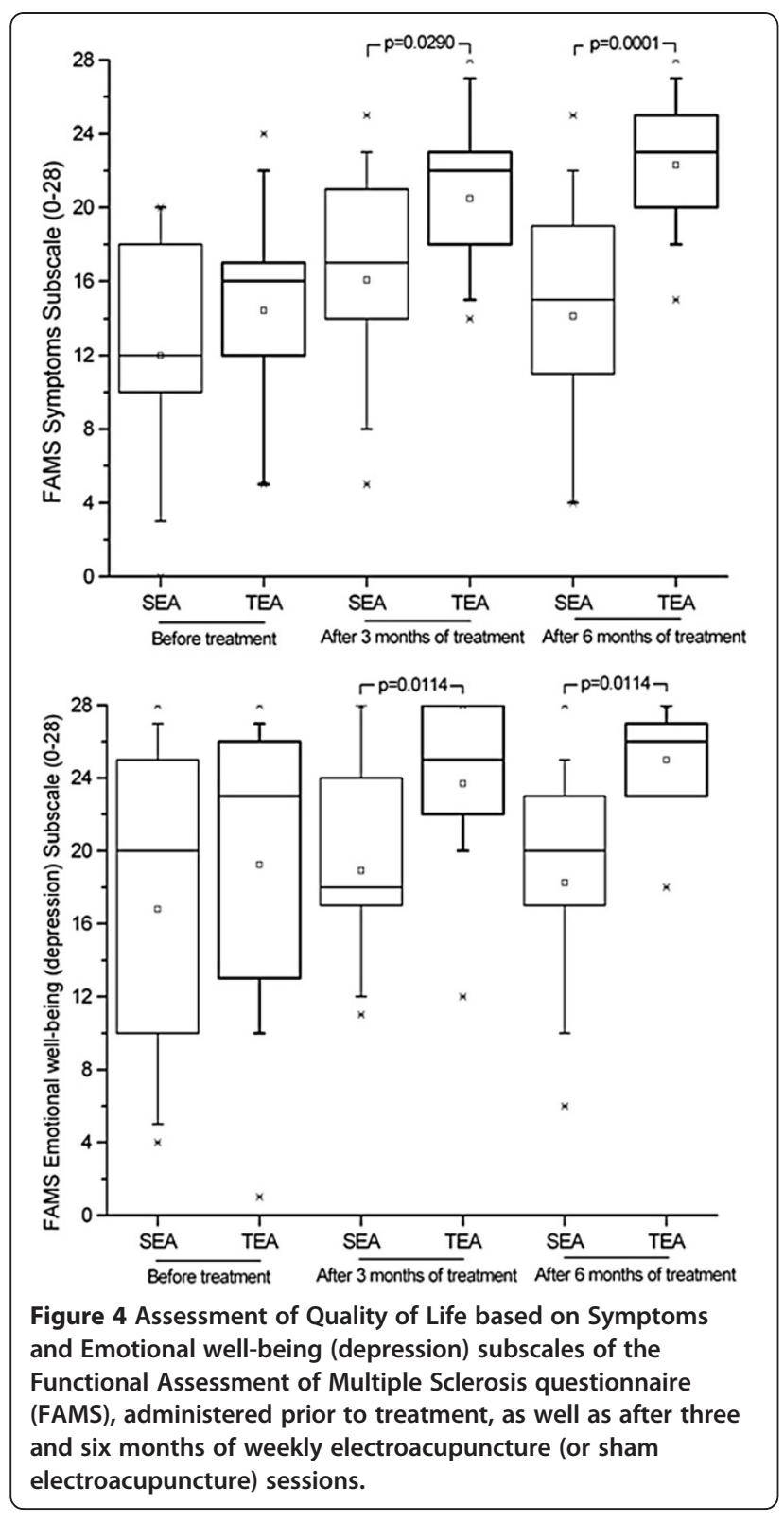

however, showed a truly significant improvement in mobility in the eyes of the patients who had received the TEA. This discrepancy in values is not surprising, since the FAMS score is considerably more subjective, and patient self-impressions are generally not assessed by the EDSS. Furthermore, the latter measures overall performance, and changes on this level take some time to appear.

The degenerative nature of the disease means that actual performance will constantly worsen, and the reduction in mobility of the patients submitted to sham electroacupuncture was noticeable, even in the short six-month period evaluated. The degeneration of those receiving TEA, however, was held in abeyance.
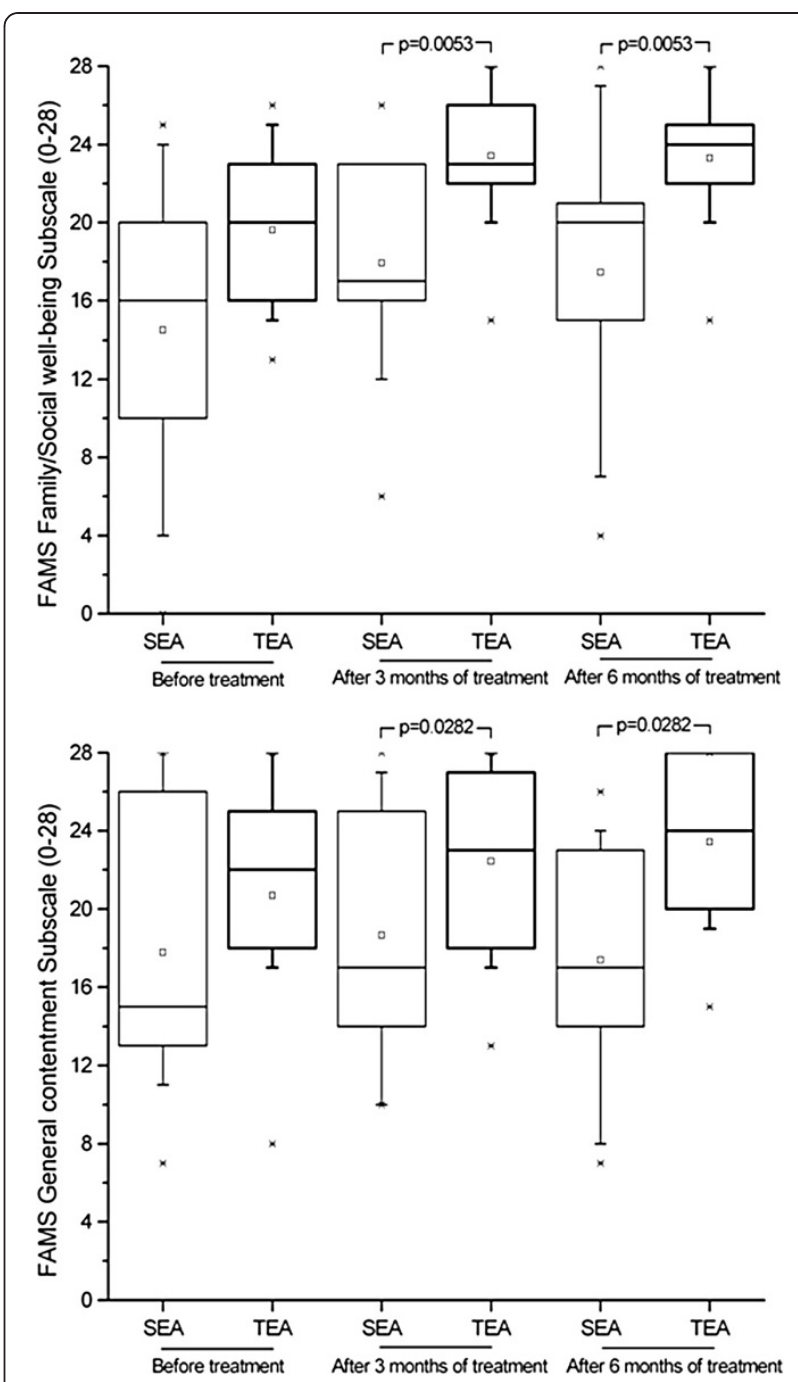

Figure 5 Assessment of Quality of Life based on Family/Social well-being, and General Contentment subscales of Functional Assessment of Multiple Sclerosis questionnaire (FAMS), administered prior to treatment, as well as after three and six months of weekly electroacupuncture (or sham electroacupuncture) sessions.

On the other hand, the patient-evaluated QOL is more sensitive to short-term alterations, which would make it possible for the doctor to observe relevant changes in the state of the patient and modify treatment to improve the situation. It is, however, the EDSS which is generally adopted for the evaluation of the mobility of the patient with RRMS. Since the results of this test ignore the quality of the life of the patient, the addition of a test such as FAMS, which does measure it, could be of great benefit to the well-being of a patient.

The life of patients with RRMS tends to be a solitary one for various reasons, not the least of which is the frequent presence of pain, which affect some $29-86 \%$ of all 


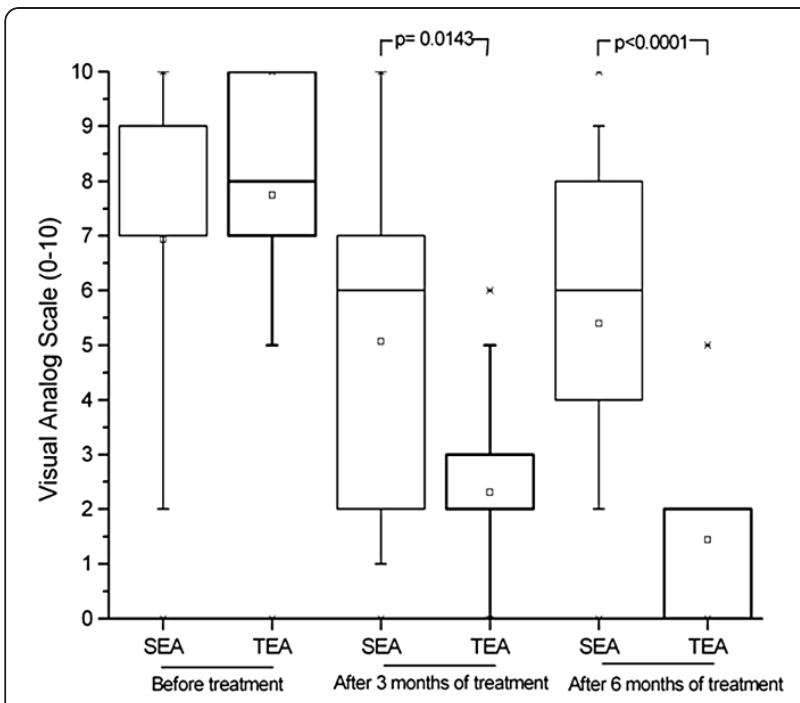

Figure 6 Assessment of pain based on results of Visual Analogue Scale (VAS) administered prior to treatment, as well as after three and six months of weekly electroacupuncture (or sham electroacupuncture) sessions.

patients [26]. A large number of publications point out that patients with chronic pain suffer from reduced social adjustment and an increase in psychiatric morbidity [27-30]. Although pain is rarely considered in the clinical evaluation of RRMS, it does seem important to deal with such a potentially incapacitating aspect of the disease, especially since the results of this study show that it can be efficiently dealt with using electroacupuncture. These results are in agreement with those of previous studies which have demonstrated the analgesic effect of acupuncture, which is known to ameliorate the deregulation of sensory information in the processing of pain [31-36].

The stigmatization of those with RRMS also contributes to the isolation of these patients; this effect is enhanced by many of the symptoms of RRMS, especially depression, which has a strong negative impact on the life of patients [37]. Depression occurs in as many as 60\% of patients with multiple sclerosis, although it is independent of the disability inherent in the clinical course of the disease [38]. Not only does depression lead to the isolation of patients from their friends and families, but, when chronic, can even lead to attempts at suicide $[6,39]$. It can, however, be largely controlled. If the depressive state of a patient can be identified, some of the damage resulting from it can be ameliorated, if not prevented. This study, for example, has shown that electroacupuncture can improve the emotional well being of RRMS patients, with results visible after only three months, although this is not normally assessed in the routine evaluation of RRMS patients.

\section{Conclusions}

A reasonable quality of life is important in stimulating the desire of an RRMS patient to live as full a life as possible. QOL, however, is not a direct reflection of the neurological development of the disease. This paper provides evidence that electroacupuncture can significantly improve various domains of the QOL of MS patients, especially pain. In normal clinical evaluations of the disease, however, emphasis is limited to physical incapacity, and QOL as such is ignored. The regular use of self-evaluation scales such as the FAMS should help identify problems which could be relieved, as well as helping evaluate the efficacy of traditional treatments, since such self-evaluations often reveal more rapid responses to treatment than do the more objective evaluations of trained professionals.

\section{Competing interests}

All authors declare that they have no competing interests.

\section{Authors' contributions}

JGQC conceived of and organized the study. All authors contributed to its realization, with JGQC, AD, FG, COB, and BPD being largely responsible for the collection of the data, and JGQC, WDS, and LMBS responsible for the organization and analysis of the data. All authors read and approved the final manuscript.

\section{Acknowledgements}

The authors would like to acknowledge the collaboration of Lucas Vilas Boas and Rafael Leme in the neurological evaluation of the patients. The study was financially supported by the Brazilian Council for the Improvement of University Personnel (CAPES) and the Foundation for the Support of Research of the State of Sao Paulo (FAPESP).

\section{Author details}

${ }^{1}$ Neuroimmunology Unit, Department of Genetics, Evolution and Bioagents, University of Campinas (UNICAMP), Campinas, SP, Brazil. ${ }^{2}$ Department of Clinical Medicine, University of Campinas (UNICAMP), Campinas, SP, Brazil. ${ }^{3}$ Department of Genetics, Evolution and Bioagents, University of Campinas (UNICAMP), Campinas, SP, Brazil. ${ }^{4}$ Department of Neurology, University of Campinas(UNICAMP), Campinas, SP, Brazil.

Received: 27 February 2012 Accepted: 12 September 2012

Published: 5 November 2012

\section{References}

1. Ramagopalan SV, Dobson R, Meier UC, Giovannoni G: Multiple Sclerosis: risk factors, prodromes and potential causal pathways. Lancet Neurol 2010, 9:727-739.

2. Giovannoni G: Promising emerging therapies for multiple sclerosis. Neurol Clin 2011, 29(2):435-448.

3. Schluep M, Bogousslavsky J: Emerging treatments in multiple sclerosis. Eur Neurol 1997, 38(3):216-221.

4. Young RR: Diagnosis and medical management of multiple sclerosis. J Spinal Cord Med 1998, 21(2):109-112.

5. Garcia-Moreno JM, Navarro G, Duque P, Gamero MA, Gata JM, Gálvez JL, Izquierdo G: Evolution and adverse effects in patients with remittentrecurrent multiple sclerosis treated with interferon beta $1 \mathrm{~b}$. The influence of patient's weight and height. Neurologia 1999, 14(4):154-158.

6. Olascoaga J: Calidad de vida y esclerosis múltiple. Rev Neurol 2010, 51:279-288.

7. Ulett GA, Han S, Han JS: Electroacupuncture: mechanisms and clinical application. Biol Psychiatry 1998, 44(2):129-138.

8. Aranha MF, Alves MC, Bérzin F, Gavião MB: Efficacy of electroacupuncture for myofascial pain in the upper trapezius muscle: a case series. Rev Bras Fisioter 2011, 15(5):371-379. 
9. Gakiya HH, Silva DA, Gomes J, Stevanin H, Cassu RN: Electroacupuncture versus morphine for the postoperative control pain in dogs. Acta Cir Bras 2011, 26(5):346-351.

10. Wu P, Mills E, Moher D, Seely D: Acupuncture in poststroke rehabilitation: a systematic review and meta-analysis of randomized trials. Stroke 2010, 41(4):171-179.

11. Zhang F, Wu Y, Jia J: Electro-acupuncture can alleviate the cerebral edema of rat after ischemia. Brain Inj 2011, 25(9):895-900.

12. Cheng XK, Wang ZM, Sun L, Li YH: Post-stroke hand dysfunction treated with acupuncture at Zhongzhu (TE 3) and Waiguan (TE 5). Zhongguo Zhen Jiu 2011, 31(2):117-120.

13. Donnellan CP, Shanley J: Comparison of the effect of two types of acupuncture on quality of life in secondary progressive multiple sclerosis: a preliminary single-blind randomized controlled trial. Clin Rehabil 2008, 22(3):195-205.

14. McDonald WI, Compston A, Edan G, Goodkin D, Hartung HP, Lublin FD, McFarland HF, Paty DW, Polman CH, Reingold SC, Sandberg-Wollheim M, Sibley W, Thompson A, van den Noort S, Weinshenker BY, Wolinsky JS: Recommended diagnostic criteria for multiple sclerosis: guidelines from the International Panel on the diagnosis of multiple sclerosis. Ann Neurol 2001, 50:121-127.

15. Polman CH, Reingold SC, Banwell B, Clanet M, Cohen JA, Filippi M, Fujihara K, Havrdova E, Hutchinson M, Kappos L, Lublin FD, Montalban X, O'Connor P, Sandberg-Wollheim M, Thompson AJ, Waubant E, Weinshenker B, Wolinsky JS: Diagnostic criteria for multiple sclerosis: 2010 revisions to the McDonald Criteria. Ann Neurol 2010, 69:292-302.

16. Kavoussi B, Ross BE: The neuroimmune basis of anti-inflammatory acupuncture. Integr Cancer Ther 2007, 6(3):251-257.

17. Joos S, Schott C, Zou H, Daniel V, Martin E: Immunomodulatory effects of acupuncture in the treatment of allergic asthma: a randomized controlled study. J Altern Complement Med 2000, 6(6):519-525.

18. Yamaguchi N, Takahashi T, Sakuma M, Sugita T, Uchikawa K, Sakaihara S, Kanda T, Arai M, Kawakita K: Acupuncture regulates leukocyte subpopulations in human peripheral blood. Evid Based Complement Alternat Med 2007, 4(4):447-453.

19. Chang $\mathrm{CH}$, Huang JL, Ting $\mathrm{CT}$, Chang $\mathrm{CS}$, Chen GH: Atropine-induced HRV alteration is not amended by electroacupuncture on Zusanli. Am J Chin Med 2005, 33(2):307-314

20. Li A, Lao L, Wang Y, Xin J, Ren K, Berman BM, Tan M, Zhang R: Electroacupuncture activates corticotrophin-releasing hormonecontaining neurons in the paraventricular nucleus of the hypothalammus to alleviate edema in a rat model of inflammation. BMC Complement Altern Med 2008, 8:20.

21. Mori H, Nishijo K, Kawamura H, Abo T: Unique immunomodulation by electro-acupuncture in humans possibly via stimulation of the autonomic nervous system. Neurosci Lett 2002, 320(1-2):21-24.

22. Ding L: Acupuncture, Meridian Theory and Acupuncture Points. Beijing: Foreing Languages Press; 1970.

23. Kurtzke JF: Rating neurologic impairment in multiple sclerosis: an expanded disability status scale (EDSS). Neurology 1983, 33(11):1444-1452.

24. Mendes MF, Balsimelli S, Stangehaus G, TILBERY CP: Validação de escala de determinação funcional da qualidade de vida na esclerose múltipla para a língua portuguesa. Arq Neuro-Psiquiatr 2004, 62(1):108-113.

25. Cella DF, Dineen K, Arnason B, Reder A, Webster KA, Karabatsos G, Chang C, Lloyd S, Steward J, Stefoski D: Validation of the functional assessment of multiple sclerosis quality of life instrument. Neurology 1996, 47:129-139.

26. Bermejo PE, Oreja-Guevara C, Díez-Tejedor E: El dolor en la esclerosis múltiple: prevalencia, mecanismos, tipos y tratamiento. Rev Neurol 2010, 50:101-108

27. Osborne TL, Jensen MP, Ehde DM, Hanley MA, Kraft G: Psychosocial factors associated with pain intensity, pain-related interference, and psychological functioning in persons with multiple sclerosis and pain. Pain 2007, 127(1-2):52-62.

28. Kalia LV, O'Connor PW: Severity of chronic pain and its relationship to quality of life in multiple sclerosis. Mult Scler 2005, 11(3):322-327.

29. Ehde DM, Osborne TL, Hanley MA, Jensen MP, Kraft GH: The scope and nature of pain in persons with multiple sclerosis. Mult Scler 2006, 12(5):629-638.

30. Svendsen KB, Jensen TS, Hansen HJ, Bach FW: Sensory function and quality of life in patients with multiple sclerosis and pain. Pain 2005, 114(3):473-481.
31. Zhao ZQ: Neural mechanism underlying acupuncture analgesia. Prog Neurobiol 2008, 85:355-375.

32. Han JS, Ho YS: Global trends and performances of acupuncture research. Neruosci Biobehav Rev 2011, 35:680-687.

33. Han JS, Terenius L: Neurochemical basis of acupuncture analgesia. Annu Rev Pharmacol Toxicol 1982, 22:91-104.

34. Marx JL: Analgesia: how the body inhibits pain perception. Science 1977, 196:471.

35. Mayer DJ, Price DD, Raffii A: Antagonism of acupuncture analgesia in man by the narcotic antagonist naloxine. Brain Res 1977, 121:368-372.

36. Pomeranz B, Chiu D: Naloxone blocks acupuncture analgesia and causes hyperalgesia: endorphin is implicated. Life Sci 1976, 19:1757-1762.

37. Janardhan V, Bakshi R: Quality of life in patients with multiple sclerosis: the impact of fatigue and depression. J Neurol Sci 2002, 205(1):51-58.

38. Bakshi R, Shaikh ZA, Miletich RS, Czarnecki D, Dmochowski J, Henschel K, Janardhan V, Dubey N, Kinkel PR: Fatigue in multiple sclerosis and its relationship to depression and neurologic disability. Mult Scler 2000 6(3):181-185.

39. Ziemssen T: Multiple sclerosis beyond EDSS: depression and fatigue. J Neurol Sci 2009, 277(1):37-41.

doi:10.1186/1472-6882-12-209

Cite this article as: Quispe-Cabanillas et al:: Impact of electroacupuncture on quality of life for patients with Relapsing-Remitting Multiple Sclerosis under treatment with immunomodulators: A randomized study. BMC Complementary and Alternative Medicine 2012 12:209.

\section{Submit your next manuscript to BioMed Central and take full advantage of:}

- Convenient online submission

- Thorough peer review

- No space constraints or color figure charges

- Immediate publication on acceptance

- Inclusion in PubMed, CAS, Scopus and Google Scholar

- Research which is freely available for redistribution 